\title{
Analisa Kondisi Ekosistem Mangrove Menggunakan Data Citra Satelit Multitemporal dan Multilevel (Studi Kasus: Pesisir Utara Surabaya)
}

\author{
Deni Ratnasari dan Bangun Muljo Sukojo \\ Departemen Teknik Geomatika, Fakultas Teknik Sipil dan Perencanaan,Institut Teknologi Sepuluh Nopember (ITS) \\ e-mail: bangunms@gmail.com
}

\begin{abstract}
Abstrak-Wilayah pesisir Utara Surabaya mengalami dinamika perubahan yang cukup cepat. Desakan pembangunan seperti pelabuhan, kawasan industri, pergudangan dan tambak telah mengancam keberadaan ekosistem mangrove, yang mana dari segi fungsi ekosistem mangrove merupakan daerah pemijah dan tempat hidup biota laut lainnya. Ekosistem mangrove adalah salah satu obyek yang bisa diindentifikasi dengan menggunakan teknologi penginderaan jauh. Data yang digunakan dalam penelitian ini adalah citra satelit Landsat 8 tahun 2013, 2014, 2015, dan 2016, citra satelit Spot 6 tahun 2016, serta data citra satelit resolusi sangat tinggi pleiades $1 \mathrm{~A}$ tahun 2015. Algoritma yang digunakan adalah NDVI (Normalized Difference Vegetation Index) untuk mengetahui tingkat kehijauan suatu jenis mangrove. Berdasarkan hasil penelitian, citra Pleiades 1A dengan skala 1:5.000 didapatkan jenis mangrove yang didominasi oleh Rhizophora sp. dengan luas 16,23 Ha. Sedangkan untuk citra Landsat 8 dengan skala 1:25.000 didapatkan kelas vegetasi mangrove yang didominasi kelas Rapat seluas 54,92 Ha. Kondisi vegetasi mangrove tahun 2013 sampai 2016 semakin memburuk dengan penurunan luas 1Ha - 5 Ha pertahun atau sekitar 1\% $5 \%$ pertahun. Faktor lingkungan yang mempengaruhi kondisi vegetasi mangrove adalah salinitas, hasil uji korelasi menunjukkan hubungan yang sangat kuat antara nilai NDVI citra dengan parameter salinitas yaitu $(R)$ sebesar 0,86 .
\end{abstract}

Kata kunci - Korelasi, NDVI,Mangrove,Penginderaan jauh.

\section{PENDAHULUAN}

$\mathrm{W}$ ILAYAH pesisir Kota Surabaya secara umum dapat dikelompokkan menjadi kawasan pesisir utara dan timur. Di kawasan pesisir utara terdapat Teluk Lamong yang menjadi muara dari Kali Lamong. Di kawasan tersebut banyak ditemui vegetasi ekosistem mangrove, tapi seiring berkembangnya Kota Surabaya menyebabkan desakan pembangunan yang cenderung mengarah ke arah pantai atau pesisir. Desakan pembangunan seperti pembangunan pelabuhan, kawasan industri, pergudangan dan tambak akan membuat kondisi air laut dan kondisi tanah di Teluk Lamong menjadi tercemar. Kondisi tersebut telah mengancam aktivitas pertumbuhan ekosistem mangrove.

Ekosistem mangrove adalah salah satu obyek yang bisa di identifikasi dengan menggunakan teknologi penginderaan jauh. Letak ekosistem mangrove yang berada pada daerah peralihan darat dan laut memberikan efek perekaman yang khas jika dibandingkan obyek vegetasi darat lainnya. Efek perekaman tersebut sangat erat kaitannya dengan karakteristik spektral ekosistem mangrove, hingga dalam identifikasi memerlukan suatu transformasi tersendiri. Pada umumnya untuk deteksi vegetasi digunakan transformasi indeks vegetasi [1].

Dalam penelitian ini akan mengkaji kondisi vegetasi ekosistem mangrove berdasarkan nilai NDVI (Normalized Difference Vegetation Index) menggunakan teknik penginderaan jauh dengan menggunakan citra satelit multitemporal dan multilevel. Selain itu dalam penelitian ini nilai NDVI citra akan divalidasi dengan data lapangan. Dari hasil penelitian diharapkan dapat memberikan suatu informasi mengenai kondisi ekosistem mangrove yang didasarkan pada pengolahan citra, sehingga dapat dijadikan sebagai bahan referensi penelitian yang terkait dengan bidang pemetaan, konservasi dan pengembangan ekosistem mangrove.

\section{METODOLOGI PENELITIAN}

\section{A. Lokasi Penelitian}

Penelitian ini dilakukan di wilayah pesisir Utara Surabaya (Teluk Lamong) yang terletak antara $7^{0} 11^{\prime} 0$ " $-7^{0} 13^{\prime} 0^{\prime \prime}$ LS dan $112^{0} 38^{\prime} 0$ " $-112^{0} 43^{\prime}$ 0" BT. Berikut merupakan gambar dari lokasi penelitian:

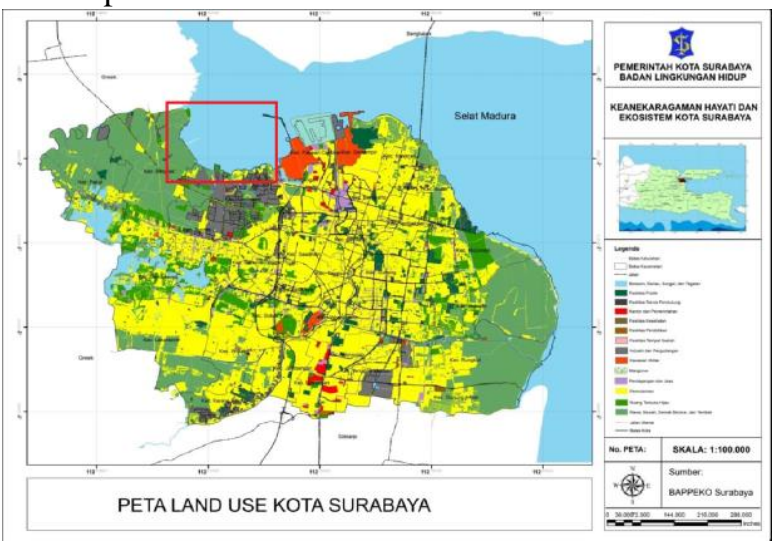

Gambar 1. Lokasi Penelitian

B. Data dan Peralatan

1) Data

Data yang digunakan dalam penelitian ini adalah:

a. Citra satelit Pleiades 1A tahun 2015

b. Citra satelit Spot 62016

c. Citra Landsat 8 tahun 2013-2016 

d. Peta RBI 1:25.000
e. Koordinat GCP hasil pengukuran GPS Geodetik
f. Data Spektral Ground yang diperoleh dari pengambilan foto di lapangan menggunakan kamera UAV
g. Data uji sampel parameter Air dan Tanah

\section{2) Peralatan}

Peralatan yang digunakan dalam penelitian ini adalah:

1. Perangkat Keras (hardware)

a.Laptop

2. Perangkat Lunak (software)

a. Software pengolah citra

b. Software pengolah statistik

c. Software pengolah layouting

3. Perangkat pengambilan data di lapangan
a.GPS Geodetik
b.GPS Navigasi
c. Kamera UAV

\section{Tahapan Pengolahan Data}

Adapun proses pengolahan data yang dilakukan adalah sebagai berikut:

a. Tahap awal meliputi Penajaman citra (pansharpening) yaitu proses perbaikan terhadap kualitas citra agar citra memiliki tampilan yang lebih tajam dengan cara menggabungkan band pankromatik dengan band multispektral. Pemotongan citra (cropping) Pemotongan citra dilakukan berdasarkan daerah yang terdapat hutan mangrove. Tujuan dari pemotongan citra ini agar penelitian fokus pada wilayah studi.

b. Pembuatan Desain Jaring Titik Kontrol dan Perhitungan SoF. Desain jaring yang telah dibuat dilakukan perhitungan Strength of Figure (SoF) untuk mengetahui nilai kekuatan jaring.

c. Koreksi Geometrik yaitu pembetulan citra secara geometrik sehingga proyeksi peta dan sistem koordinat yang digunakan sesuai dengan dunia nyata. Koreksi Geometrik(rektifikasi) pada citra Pleiades 1A dan SPOT 6 dengan bantuan pengambilan titik Ground Control Point (GCP) dilapangan menggunakan GPS Geodetik sedangakan acuan untuk citra Landsat 8 menggunakan peta RBI skala 1:25.000. Dalam melakukan koreksi geometrik hasil dari RMSE harus $\leq 1$ piksel [2].

d. Uji Ketelitian Geometrik yaitu Pengujian ketelitian posisi mengacu pada perbedaan koordinat $(\mathrm{X}, \mathrm{Y})$ antara titik uji pada gambar atau peta dengan lokasi sesungguhnya dari titik uji pada permukaan tanah. Pengukuran akurasi menggunakan root mean square error (RMSE) atau circular error.

$$
\begin{aligned}
& \text { RMSE }_{\text {horizontal }}=\sqrt{D^{2} / n} \\
& =\sqrt{\frac{\sum\left[\left(x_{d a t a}-x_{c a k}^{c}\right)^{2}+\left(y_{d a t a}-y_{c a k}\right)^{2}\right]}{n}}
\end{aligned}
$$

Keterangan:

$\mathrm{n} \quad=$ jumlah total pengecekan pada peta

$\mathrm{D}=$ selisih antara koordinat yang diukur di lapangan dengan koordinat di peta

$\mathrm{x}$ = nilai koordinat pada sumbu $-\mathrm{X}$

$\mathrm{y}=$ nilai koordinat pada sumbu $\mathrm{Y}$

e. Koreksi Radiometrik untuk memperbaiki nilai piksel agar sesuai dengan yang seharusnya yang biasanya mempertimbangkan faktor gangguan atmosfer sebagai sumber kesalahan utama [3]. Koreksi Radiometrik meliputi kalibrasi radiometrik dan koreksi atmosfer. Kalibrasi radiometrik melakukan konversi DN (Digital Number) ke Radiance/reflektan kemudian koreksi atmosfer dengan metode 6SV.

f. Perhitungan Algoritma Indeks Vegetasi yaitu melakukan pengolahan indeks vegetasi NDVI dengan cara memasukkan algoritma indeks vegetasi. Algoritma NDVI sebagai berikut:

$$
\mathrm{NDVI}=\frac{N I R-R E D}{N I R+R E D}
$$

Keterangan :

NIR $=$ Nilai band spektral inframerah dekat

RED $=$ Nilai band spektral merah

g. Klasifikasi algoritma NDVI dengan memasukkan range nilai tiap jenis kerapatan vegetasi [4].

$$
\text { Tabel } 1 .
$$

Tingkat Kerapatan Vegetasi

\begin{tabular}{ccc}
\hline \hline Kelas & Kisaran NDVI & Tingkat Kepuasan \\
\hline 1 & 0 s.d 0,32 & Jarang \\
2 & 0,32 s.d 0,42 & Sedang \\
3 & $>0,42$ s.d 1 & Tinggi \\
\hline \hline
\end{tabular}

Sumber:Departemen Kehutanan 2003

h. Observasi lapangan (Ground Truth) yaitu pengambilan data lapangan berupa koordinat Ground Control Point (GCP), Sampel parameter air dan tanah dan pengambilan foto menggunakan kamera UAV.

i. Uji korelasi dilakukan untuk mengetahui hubungan antar variabel. Dalam penelitian ini nilai NDVI citra sebagai variabel $x$ dan uji sampel dilapangan sebagai variabel $y$. Dilakukan 3 uji korelasi yaitu uji korelasi nilai NDVI citra dengan nilai NDVI foto di lapangan, uji korelasi nilai NDVI citra dengan sampel parameter air dan uji korelasi NDVI citra dengan sampel parameter tanah.

j. Analisa kondisi ekosistem mangrove berdasarkan nilai algoritma indeks vegetasi NDVI dan parameter di lapangan.

\section{HASIL DAN ANALISA}

\section{A. Koreksi Geometrik dan Perhitungan Strength of Figure}

Koreksi geometrik (rektifikasi) citra Pleiades 1A dan Spot 6 menggunakan 4 titik GCP yang mana titik GCP tersebut telah mewakili kelas mangrove. Perhitungan Strenght of Figure (SoF) citra Pleiades 1A dan Landsat 8 berturut-turut sebesar 0,208 dan 0,149 dan telah masuk toleransi yang disyaratkan yaitu kurang dari 1, sehingga desain jaring SoF dianggap kuat $^{[5]}$. Hasil koordinat titik GCP telah terikat dengan titik 
kontrol SRGI dan diperoleh hasil RMS citra Pleiades 1A sebesar 0,41 dan SPOT6 0,54. Koreksi geometrik Landsat 8 tahun 2013-2016 menggunakan peta RBI 1:25.000 dengan 5 titik GCP diperoleh RMS sebesar 0,22, 0,24, 0,22, dan 0,26. Uji Ketelitian geometrik untuk citra Pleiades 1A sebesar 0,956 m sedangkan untuk citra SPOT 6 sebesar 1,125 m sehingga hal ini telah memenuhi syarat untuk skala 1:5000 yaitu masuk kelas 1untuk citra Pleiades 1A dan masuk kelas 2 untuk citra SPOT 6 [2].

\section{B. Klasifikasi Kondisi Ekosistem Mangrove Berdasarkan Nilai Indeks Vegetasi NDVI}

Klasifikasi untuk tingkat kondisi kerapatan vegetasi mangrove di wilayah pesisir Utara Surabaya menggunakan klasifikasi tak terbimbing (unsupervised) dengan menggunakan hasil penerapan algoritma NDVI. Klasifikasi berdasarkan Departemen Kehutanan tahun 2003 untuk citra Pleiades 1A dibagi menjadi 3 kelas menurut jenis ekosistem mangrove sedangkan klasifikasi Landsat 8 dibagi menjadi 3 kelas menurut kerapatan yaitu jarang, sedang dan rapat. Berikut hasil penerapan algoritma pada citra Pleiades 1A dan Landsat 8.

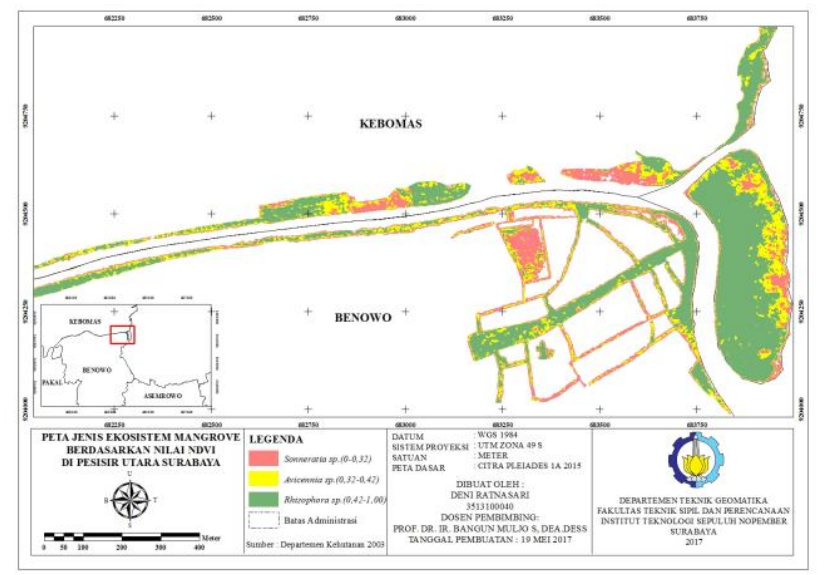

Gambar 2. Peta Jenis Ekosistem Mangrove Tahun 2015

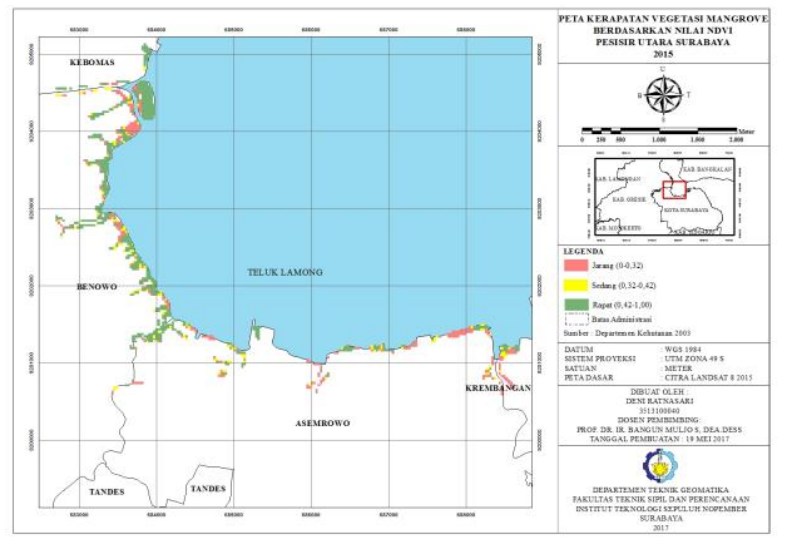

Gambar 3. Peta Kondisi Ekosistem Mangrove Tahun 2015
Tabel 2.

Luas (Ha) Jenis Ekosistem Mangrove citra Pleiades 1A

\begin{tabular}{cccc}
\hline \hline No & NDVI & Jenis & Luas (Ha) \\
\hline 1 & $0-0,32$ & Sonneratia sp. & 6,69 \\
2 & $3,2-0,42$ & Avicennia sp. & 6,24 \\
3 & $0,42-1$ & Rhizophora sp. & 16,23 \\
\hline \hline
\end{tabular}

Sumber:Hasil Pengolahan

Tabel 3.

Luas (Ha) Kondisi Kerapatan Mangrove citra landsat 8

\begin{tabular}{ccccc}
\hline \hline Tahun & Jarang & Sedang & Rapat & Luas Total \\
\hline 2013 & 19,89 & 8,82 & 69,75 & 98,46 \\
2014 & 32,19 & 17,73 & 47,97 & 97,89 \\
2015 & 27,09 & 12,24 & 56,88 & 96,21 \\
2016 & 38,25 & 7,92 & 45,08 & 91,25 \\
\hline \hline
\end{tabular}

Sumber:Hasil Pengolahan

Berdasarkan tabel 3 Luas total mangrove di wilayah pesisir Utara Surabaya tiap tahunnya semakin menurun sebanyak 1\%$5 \%$ atau $1 \mathrm{Ha}-5 \mathrm{Ha}$. Hal tersebut dikarenakan adanya perkembangan pembangunan yang cukup pesat di wilayah Utara Surabaya seperti pembangunan Pelabuhan, Industri, Pergudangan dan Tambak. Perkembangan tersebut menjadikan aktivitas pertumbuhan mangrove terganggu oleh pencemaran lingkungan. Jika mengacu pada Keputusan Menteri Negara Lingkungan Hidup Nomor 201 tahun 2004 tentang Kriteria Baku dan Pedoman Penentuan Kerusakan Hutan Mangrove. Hutan mangrove di Pesisir utara Surabaya dalam kondisi baik menuju rusak dengan kerapatan pohon $<1500$ pohon/Ha dan penutupan antara $40-60 \%$.

\section{Hubungan Korelasi antara Nilai Algoritma NDVI Citra dengan Spektral Ground di Lapangan}

Hubungan korelasi antara nilai algoritma NDVI citra dengan spektral ground di lapangan dapat diketahui melalui uji korelasi antar 2 variabel. Sebaran titik yang digunakan dalam uji korelasi yang mendeskripsikan hubungan antara nilai NDVI pada citra dengan nilai Spektral Ground, sebagai berikut :

Tabel 4.

Data Nilai NDVI pada Citra terhadap Spektral Ground di Lapangan

\begin{tabular}{cccrcrr}
\hline \hline \multirow{2}{*}{$\begin{array}{c}\text { Nama } \\
\text { Titik }\end{array}$} & \multicolumn{2}{c}{ Koordinat } & \multicolumn{4}{c}{ Nilai NDVI } \\
& X $)$ & Y $(\mathrm{m})$ & \multicolumn{1}{c}{ Pleiades } & $\begin{array}{c}\text { Lands } \\
\text { at } 8\end{array}$ & \multicolumn{1}{c}{ SPOT } & \multicolumn{1}{c}{ Foto } \\
\hline \multirow{2}{*}{ R1 } & 683787 & 920406 & 0,16868 & 0,2230 & 0,230 & 0,166 \\
&, 79 & 4,44 & 6 & 42 & 769 & 667 \\
& 683772 & 920405 & 0,23252 & 0,2527 & 0,313 & 0,211 \\
R2 &, 81 & 8,97 & 9 & 53 & 433 & 823 \\
& 683759 & 920405 & 0,47298 & 0,4175 & 0,514 & 0,352 \\
R3 &, 63 & 2,3 & 4 & 96 & 545 & 518 \\
& 683545 & 920457 & 0,11931 & 0,3029 & 0,158 & 0,132 \\
P1 &, 32 & 9,08 & 1 & 02 & 974 & 42 \\
& 683539 & 920459 & 0,16470 & 0,2560 & 0,205 & 0,267 \\
P2 &, 37 & 8,26 & 2 & 38 & 172 & 606 \\
& 683527 & 920461 & 0,40589 & 0,3954 & 0,365 & 0,308 \\
P3 &, 46 & 3,48 & 2 & 28 & 079 & 642 \\
& 683953 & 920499 & 0,10874 & 0,4452 & 0,210 & 0,185 \\
K1 &, 89 & 2,23 & 7 & 64 & 526 & 52 \\
& 683933 & 920499 & 0,21534 & 0,4631 & 0,228 & 0,263 \\
K2 &, 05 & 5,54 & 2 & 48 & 07 & 158 \\
& 683914 & 920499 & 0,39363 & 0,4703 & 0,356 & 0,390 \\
K3 &, 86 & 9,17 & 9 & 78 & 643 & 728 \\
\hline \hline
\end{tabular}

Dari hasil uji korelasi NDVI citra Pleiades 1A dengan foto 
di lapangan didapatkan nilai $\mathrm{R}^{2}$ sebesar 0,76 atau koefisien korelasinya $(\mathrm{R})$ sebesar 0,87 . Sehingga dapat dikatakan antara nilai NDVI pada citra Pleiades 1A dan foto berkorelasi sangat kuat sebesar $87 \%$.

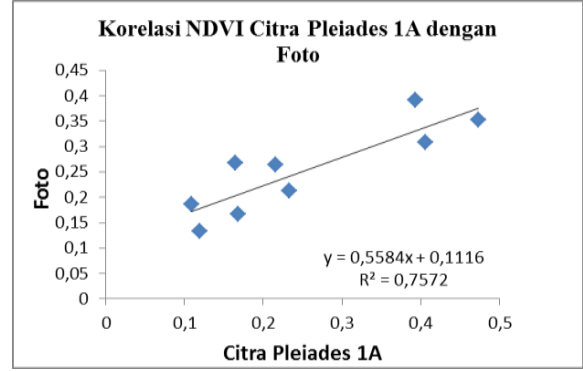

Gambar 4. Hasil Korelasi NDVI citra Pleiades 1A dengan Foto

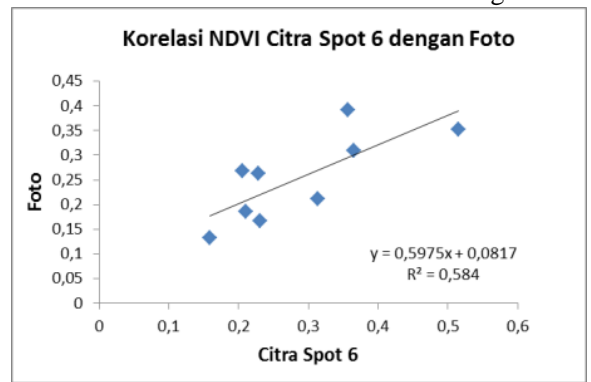

Gambar 5.Hasil Korelasi NDVI citra Spot 6 dengan Foto

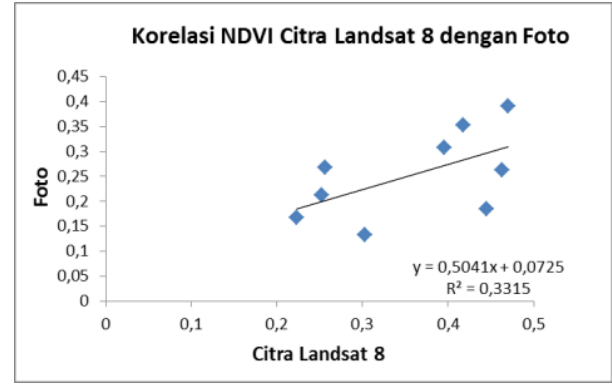

Gambar 7. Hasil Korelasi NDVI citra Landsat 8 dengan Foto

Hasil uji korelasi NDVI citra Spot 6 dengan foto didapatkan nilai (R) 0,76 sehingga hubungan NDVI citra Spot 6 dengan Foto Kuat berkorelasi sebesar $76 \%$. Sedangkan Landsat 8 dengan foto didapatkan nilai (R) sebesar 0,56. Sehingga dapat dikatakan antara nilai NDVI pada citra Landsat 8 dengan foto berkorelasi sedang sebesar $56 \%$. Koefisien korelasi bertanda positif artinya hubungan nilai NDVI pada citra dengan foto satu arah, sehingga jika nilai NDVI semakin tinggi maka nilai NDVI foto juga semakin tinggi. Sehingga penggunaan NDVI pada citra Pleiades 1A paling optimal untuk analisa jenis ekosistem mangrove di pesisir Utara Surabaya.

\section{Hubungan Korelasi antara Nilai Algoritma NDVI Citra dengan Sampel Parameter}

Analisis korelasi bertujuan untuk mengukur kekuatan hubungan linear antara dua variabel. Metode regresi linier digunakan untuk mengetahui hubungan antar variabel yang memiliki banyak parameter.

Tabel 5.

Nilai Indeks Vegetasi (NDVI) dengan Uji Sampel Parameter Tanah

\begin{tabular}{|c|c|c|c|c|c|c|c|c|c|c|c|c|}
\hline \multirow{2}{*}{$\begin{array}{l}\text { Nama } \\
\text { Titik }\end{array}$} & \multicolumn{2}{|c|}{ Koordinat } & \multirow{2}{*}{$\begin{array}{c}\text { NDVI } \\
\text { Pleiades } \\
1 \mathrm{~A}\end{array}$} & \multirow{2}{*}{$\begin{array}{c}\text { Jenis } \\
\text { Mangrove }\end{array}$} & \multicolumn{3}{|c|}{$\begin{array}{c}\text { Jenis } \\
\text { Tanah }\end{array}$} & \multirow{3}{*}{$\begin{array}{c}\text { Lanau } \\
(\%)\end{array}$} & \multirow{2}{*}{$\begin{array}{c}\mathrm{N} \\
\% \mathrm{~N}\end{array}$} & \multirow{2}{*}{$\begin{array}{c}\mathrm{P} \\
\% \mathrm{P}\end{array}$} & \multirow{2}{*}{$\begin{array}{c}\mathrm{K} \\
(\mathrm{ppm})\end{array}$} & \multirow{2}{*}{$\mathrm{pH}$} \\
\hline & $X$ & $\mathrm{Y}$ & & & $\begin{array}{c}\text { Kerikil } \\
(\%)\end{array}$ & $\begin{array}{c}\text { Pasir } \\
(\%)\end{array}$ & Lempung (\%) & & & & & \\
\hline R1 & $683.787,79$ & $9.204 .064,44$ & 0,169 & Sonneratia sp. & 18,01 & 52,42 & 19,02 & & 0,3 & 0,19 & 1710,9 & 7,5 \\
\hline $\mathrm{R} 2$ & $683.772,81$ & $9.204 .058,97$ & 0,233 & Avicennia sp. & 2,037 & 16,9 & 52,14 & 28,93 & 0,77 & 0,24 & 1849,6 & 7,9 \\
\hline $\mathrm{R} 3$ & $683.759,63$ & $9.204 .052,30$ & 0,473 & Rhizopora sp. & 1,936 & 14,52 & 53,73 & 29,81 & 1,17 & 0,31 & 2447,5 & 7,6 \\
\hline $\mathrm{P} 1$ & $683.545,32$ & $9.204 .579,08$ & 0,119 & Sonneratia sp. & 13,63 & 41,57 & 28,82 & 15,99 & 0,57 & 0,21 & 1012,2 & 7,5 \\
\hline $\mathrm{P} 2$ & $683.539,37$ & $9.204 .598,26$ & 0,164 & Avicennia sp. & 1,748 & 8,962 & 57,43 & 31,86 & 0,61 & 0,23 & 2418,4 & 7,9 \\
\hline P3 & $683.527,46$ & $9.204 .613,48$ & 0,406 & Rhizopora sp. & 2,096 & 15,73 & 52,85 & 29,32 & 0,92 & 0,21 & 2836,1 & 7,9 \\
\hline K1 & $683.953,89$ & $9.204 .992,23$ & 0,109 & Sonneratia sp. & 15,66 & 47,75 & 23,53 & 13,06 & 0,51 & 0,16 & 1546,9 & 7,7 \\
\hline $\mathrm{K} 2$ & $683.933,05$ & $9.204 .995,54$ & 0,215 & Avicennia sp. & 2,178 & 13,32 & 54,35 & 30,15 & 0,56 & 0,22 & 2715,1 & 7,9 \\
\hline $\mathrm{K} 3$ & $683.914,86$ & $9.204 .999,17$ & 0,394 & Rhizopora sp. & 1,958 & 14,69 & 53,61 & 29,74 & 1,56 & 0,39 & 3784,7 & 8 \\
\hline
\end{tabular}

Sumber:Hasil Uji Laboratorium

Hasil uji korelasi NDVI dengan parameter tanah dijelaskan dalam bentuk grafik pada gambar $6-9$

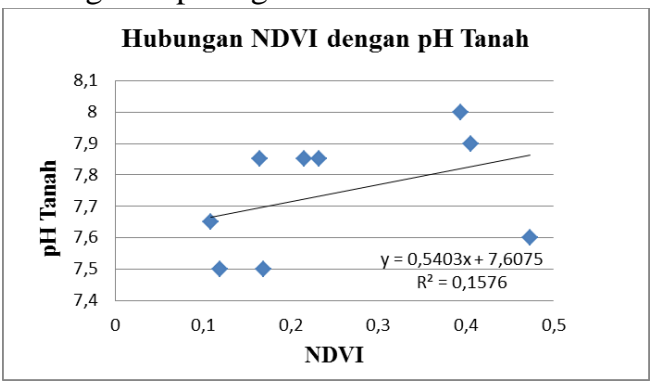

Gambar 6. Grafik hubungan NDVI dengan $\mathrm{pH}$ tanah

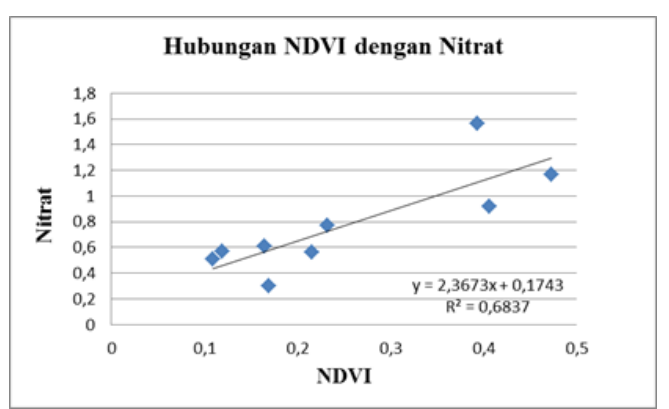

Gambar 7. Grafik hubungan NDVI dengan Nitrat 


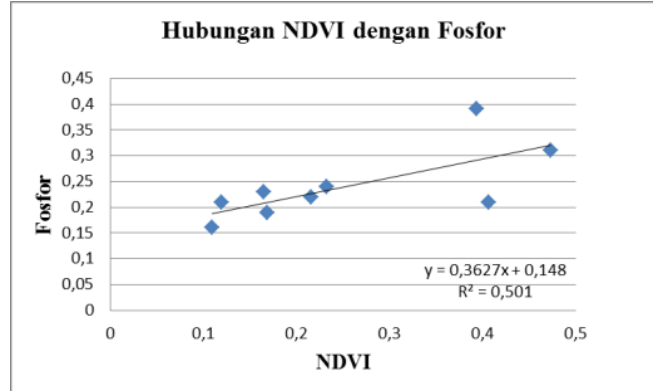

Gambar 8. Grafik hubungan NDVI dengan Fosfor

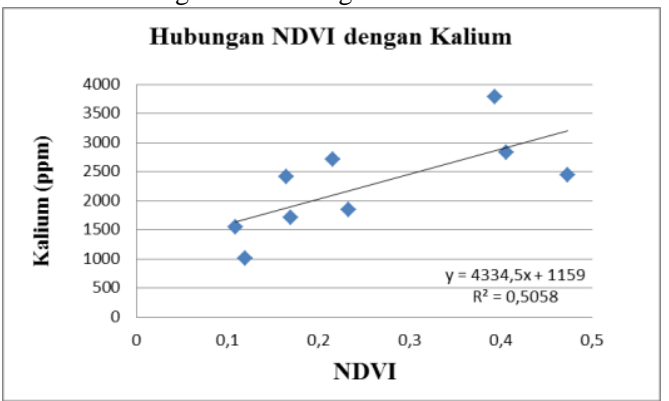

Gambar 9. Grafik hubungan NDVI dengan Kalium

Hasil uji korelasi antara NDVI dengan unsur hara Nitrat, Fosfor, dan Kalium tinggi dengan nilai (R) sebesar 0,83, 0,71, dan 0,72 hal ini menunjukkan bahwa terdapat hubungan yang kuat antara nilai NDVI dan unsur hara NPK. Koefisien korelasi bertanda positif artinya hubungan nilai NDVI dengan parameter unsur hara satu arah, jika nilai NDVI semakin tinggi maka unsur hara NPK juga semakin tinggi hal ini dikarenakan ekosistem mangrove membutuhkan unsur hara NPK untuk proses fotosintesis. Tumbuhan dengan kandungan N,P,K yang cukup daunnya akan berwarna lebih hijau ${ }^{[7]}$. Daun yang lebih hijau ini menyebabkan nilai reflektan pada citra lebih tinggi.

Korelasi antara NDVI dengan $\mathrm{pH}$ termasuk kedalam korelasi dengan hubungan tingkat sedang dengan nilai $(\mathrm{R})$ sebesar 0,41. Koefisien korelasi bertanda positif artinya hubungan nilai NDVI dengan parameter $\mathrm{pH}$ satu arah sehingga jika nilai NDVI semakin tinggi maka nilai $\mathrm{pH}$ juga semakin tinggi.

Tabel 6.

Nilai Indeks Vegetasi (NDVI) dengan Uji Sampel Parameter Air

\begin{tabular}{|c|c|c|c|c|c|c|}
\hline \multirow{2}{*}{$\begin{array}{c}\text { Nama } \\
\text { titik }\end{array}$} & \multicolumn{2}{|c|}{ Koordinat } & \multirow{2}{*}{$\begin{array}{c}\text { NDVI } \\
\text { Pleiades }\end{array}$} & \multirow{2}{*}{$\begin{array}{c}\text { Jenis } \\
\text { Mangrove }\end{array}$} & \multirow{2}{*}{$\mathrm{pH}$} & \multirow{2}{*}{$\begin{array}{c}\text { Salinita } \\
\text { s } \\
(\mathrm{ppt})\end{array}$} \\
\hline & $\mathrm{X}$ & $\mathrm{Y}$ & & & & \\
\hline K1 & $\begin{array}{c}68395 \\
4\end{array}$ & $\begin{array}{c}920499 \\
2\end{array}$ & 0,169 & $\begin{array}{c}\text { Sonnerati } \\
\text { a sp. }\end{array}$ & $\begin{array}{l}7, \\
8\end{array}$ & 0,34 \\
\hline $\mathrm{P} 1$ & $\begin{array}{c}68354 \\
5\end{array}$ & $\begin{array}{c}920457 \\
9\end{array}$ & 0,119 & $\begin{array}{c}\text { Sonnerati } \\
\text { a sp. }\end{array}$ & $\begin{array}{c}6 \\
8\end{array}$ & 0,36 \\
\hline $\mathrm{R} 1$ & $\begin{array}{c}68378 \\
8\end{array}$ & $\begin{array}{c}920406 \\
4\end{array}$ & 0,109 & $\begin{array}{c}\text { Sonnerati } \\
\quad \text { a sp. }\end{array}$ & $\begin{array}{l}7, \\
2\end{array}$ & 0,37 \\
\hline
\end{tabular}

Sumber:Hasil Uji Laboratorium

Hasil uji korelasi NDVI dengan parameter air dijelaskan dalam bentuk grafik pada gambar $10-12$

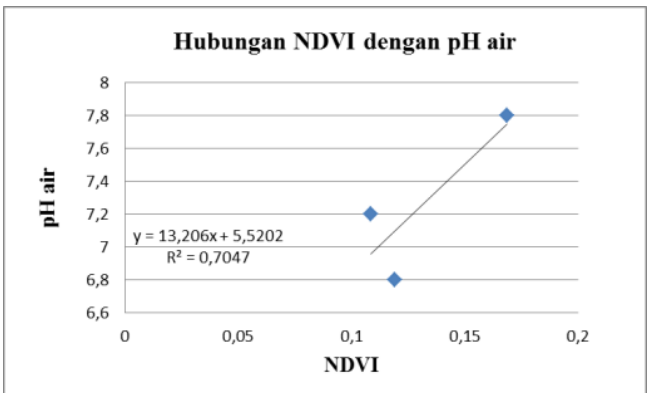

Gambar 10. Grafik hubungan NDVI dengan $\mathrm{pH}$ air

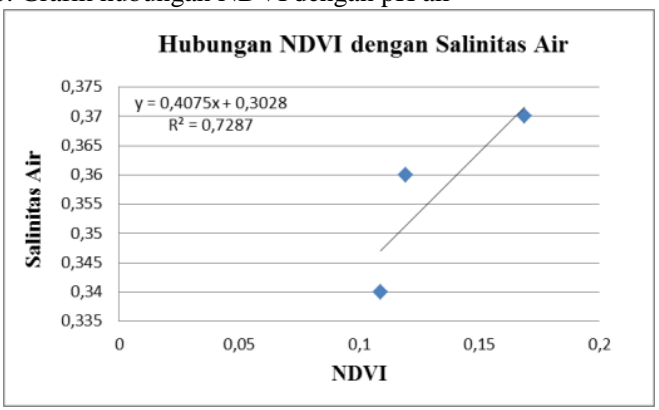

Gambar 11. Grafik hubungan NDVI dengan Salinitas air

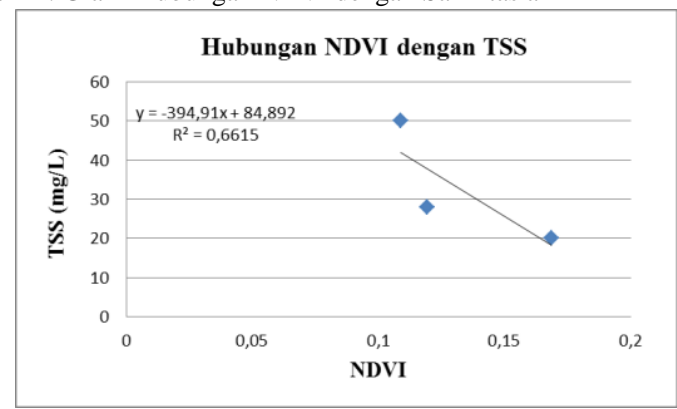

Gambar 12. Grafik hubungan NDVI dengan TSS

Korelasi NDVI dengan parameter air termasuk korelasi dengan hubungan sangat kuat dengan nilai (R) berturut-turut 0,83, 0,86, -0,81. Koefisien korelasi NDVI dengan parameter $\mathrm{pH}$ dan salinitas positif artinya semakin tinggi nilai NDVI maka semakin tinggi pula nilai $\mathrm{pH}$ dan salinitas air sedangkan koefisien korelasi NDVI dengan TSS negatif artinya semakin tinggi nilai NDVI maka nilai TSS semakin rendah hal ini dikarenakan TSS yang tinggi berindikasi adanya pencemaran sehingga menyebabkan warna daun pada mangrove tidak lagi hijau. Sehingga parameter yang T§Erhubungan erat dengan ekosistem mangrove yaitu (rghinitas.

\section{E20 Jenis Ekosistem Mangrove di Pesisir Utara Surabaya} ${ }_{28}$ Jenis mangrove di pesisir Utara Surabaya terdiri dari jenis Sonneratia sp., Avicennia sp., dan Rhizopora sp. masingnäsing dari jenis tersebut mempunyai karakteristik tersendiri [ग].

\section{Sonneratia sp.}

Sonneratia sp. biasanya hidup pada zona yang paling dekat dengan laut, dengan karakteristik daun memiliki kulit dan tersusun tunggal bersilangan, berbentuk oblong sampai bulat telur terbalik, didominasi oleh substrat agak berpasir dengan presentase pasir 52,4\%, lempung 23,7\% dan Lanau $13,1 \%$. Sonneratia sp. cenderung mendominasi daerah 
berpasir, sementara Avicennia sp. dan Rhizophora sp. cenderung untuk mendominasi daerah yang lebih berlumpur [6].

Salinitas area yang digenangi oleh air tawar atau air payau rata-rata sebesar $0.35 \mathrm{ppt}$, untuk $\mathrm{pH}$ air rata-rata 7.8. Dari hasil uji sampel di lapangan TSS di pesisir kali Lamong ratarata sebesar $33 \mathrm{mg} / \mathrm{L}$ sehingga sangat mempengaruhi warna dari daun jenis Sonneratia $s p$. Karakteristik ekosistem mangrove mampu hidup pada kadar garam yang tinggi yaitu salinitas air tambak berkisar 10-35 ppt, dan salinitas area yang digenangi oleh air payau atau air asin dengan salinitas 10 -30 ppt dan area yang digenangi oleh air tawar atau air payau dengan salinitas $0-10 \mathrm{ppt}$, pH 6-9, TSS $<20 \mathrm{mg} / \mathrm{l}[6]$. Unsur hara pada jenis Sonneratia sp. dengan presentase $\mathrm{N}=$ $0,46 \% \mathrm{P}=0,20 \%$ dan $\mathrm{K}=1423,30 \mathrm{ppm} / \mathrm{K}$ paling rendah, kandungan $\mathrm{N}$ yang rendah menyebabkan warna daun mangrove tidak hijau sehingga nilai reflektan daun mangrove lebih rendah yaitu antara 0-0,32. Tumbuhan dengan kandungan $\mathrm{N}$ yang cukup daunnya akan berwarna lebih hijau [6].

\section{Avicennia sp.}

Jenis Ekosistem Avicennia sp. terletak dibelakang zona Sonneratia sp. dengan karakteristik daun berbentuk tunggal, bertangkai, berhadapan, bertepi rata, berujung runcing atau membulat. Substrat tanah didominasi oleh lempung 54,6\%, Pasir $13,0 \%$ dan lanau 30,3\%. Untuk kandungan unsur hara pada Avicennia sp. agak sedikit lebih tinggi dibandingkan dengan zona Sonneratia $s p$. yaitu dengan presentase $\mathrm{N}=0,65 \% \mathrm{P}=0,23 \% \mathrm{~K}=2327,68 \mathrm{ppm} / \mathrm{K}$, dengan kondisi unsur hara yang lebih tinggi maka pada zona ini mendukung untuk pertumbuhan mangrove jenis Avicennia sp. hal ini dinyatakan dengan nilai reflektan dengan rentang nilai 0,32-0,42.

\section{Rhizophora sp.}

Jenis ekosistem mangrove Rhizophora $s p$. terletak di zona belakang dengan karakteristik daun tebal memiliki kulit dengan gagang daun berwarna hijau, daun berbentuk elips melebar hingga bulat memanjang dan ujungnya meruncing. Keadaan substrat tanah lempung dan lanau mendominasi yaitu sebesar $53,39 \%$ dan $29,62 \%$. Untuk salinitas sangat rendah dan cenderung tawar hal ini dikarenakan pada zona (Rhizophora sp.) hanya terendam pasang dua kali dalam sebulan. Sedangkan untuk unsur hara mendukung untuk pertumbuhan mangrove dengan nilai $\mathrm{N}=1,22 \%, \mathrm{P}=0,31 \%, \mathrm{~K}=3022,75 \mathrm{ppm} / \mathrm{K}$. Rhizophora $s p$. memiliki unsur hara yang tinggi sehingga nilai NDVI pada citra $>0,42$.

\section{KESIMPULAN DAN SARAN}

\section{A. Kesimpulan}

Berdasarkan hasil penelitian ini, dapat disimpulkan sebagai berikut :

1) Berdasarkan pengolahan citra secara geometrik (luas) dan radiometrik (klasifikasi) untuk citra Pleiades 1A dengan skala 1:5.000 didapatkan jenis mangrove yang didominasi oleh Rhizophora $s p$. dengan luas 16,23 Ha. Sedangkan untuk citra Landsat 8 dengan skala 1:25.000 didapatkan kelas vegetasi mangrove yang didominasi kelas Rapat seluas 54,92 Ha.

2) Dari hasil klasifikasi kerapatan vegetasi mangrove, kondisi vegetasi mangrove tahun 2013 sampai 2016 semakin memburuk dengan penurunan luas sekitar $1 \%$ $5 \%$ pertahun.

3) Faktor lingkungan yang mempengaruhi kondisi vegetasi mangrove adalah salinitas, hasil uji korelasi menunjukkan hubungan yang sangat kuat antara nilai NDVI citra dengan parameter salinitas yaitu (R) sebesar 0,86 .

\section{B. Saran}

Adapun saran yang diberikan dari hasil penelitian ini adalah sebagai berikut:

1. Untuk penelitian selanjutnya seharusnya menggunakan citra SPOT dengan band NIR agar hasil klasifikasinya lebih baik.

2. Untuk perolehan luas hutan mangrove yang lebih baik, pemilihan citra hendaknya yang bebas atau minim dari tutupan awan dikarenakan akan sangat mempengaruhi terhadap hasil perhitungan luas.

3. Pengambilan data lapangan uji sampel sebaiknya lebih dari 3 sampel agar hasil uji korelasi semakin baik.

\section{DAFTAR PUSTAKA}

[1] P. Danoedoro, "Pengolahan Citra Digital: "Teori dan aplikasinya dalam bidang Penginderaan Jauh,” UGM, 1996.

[2] H. . Abidin, Survei dengan GPS. Jakarta: Pradnya Paramita, 2002.

[3] S. . Soenarmo, "Penginderaan Jauh Dan Pengenalan Sistem Informasi Geografi Untuk Bidang Ilmu Kebumian,” 2009.

[4] D. Kehutanan, Buku Panduan Rehabilitasi Lahan dan Perhutanan Sosial. Jakarta: Badan Penelitian dan Pengembangan Kehutanan Departemen Kehutanan, 2003.

[5] Kusumaningrum, "Analisa Kesehatan Vegetasi Mangrove Berdasarkan Nilai Normalized Differencce Vegetation Index(NDVI) Menggunakan Citra Alos," ITS, 2013.

[6] W. Macnae, "A General Account of the Fauna of the Mangrove Swamps of Inhaca Island, Mozambique," J. Ecol, pp. 93-128, 1968. 